\title{
Technical Investigation into the In-situ Electron Backscatter Diffraction Analysis for the Recrystallization Study on Extra Low Carbon Steels
}

\author{
Ju-Heon Kim ${ }^{1,2}$, Dong-lk Kim ${ }^{1, *}$, Jong Seok Kim³ ${ }^{3}$ Shi-Hoon $\mathrm{Choi}^{3}$, Kyung-Woo $\mathrm{Yi}^{2}$, Kyu Hwan Oh${ }^{2}$ \\ ${ }^{1}$ High Temperature Energy Materials Research Center, Korea Institute of Science and Technology, Seoul 136-791, Korea \\ ${ }^{2}$ Department of Materials Science and Engineering, Seoul National University, Seoul 151-742, Korea \\ ${ }^{3}$ Department of Materials Science and Metallurgical Engineering, Sunchon National University, Suncheon 540-950, Korea
}

*Correspondence to:

Kim DI,

Tel: +82-2-958-5432

Fax: +82-2-958-5379

E-mail: dongikkim@kist.re.kr

Received June 12, 2013

Revised June 20, 2013

Accepted June 20, 2013
Technical investigation to figure out the problems arising during in-situ heating electron backscatter diffraction (EBSD) analysis inside scanning electron microscopy (SEM) was carried out. EBSD patterns were successfully acquired up to $830^{\circ} \mathrm{C}$ without degradation of EBSD pattern quality in steels. Several technical problems such as image drift and surface microstructure pinning were taking place during in-situ experiments. Image drift problem was successfully prevented in constant current supplying mode. It was revealed that the surface pinning problem was resulted from the $\mathrm{TiO}_{2}$ oxide particle formation during heating inside SEM chamber. Surface pinning phenomenon was fairly reduced by additional platinum and carbon multi-layer coating before in-situ heating experiment, furthermore was perfectly prevented by improvement of vacuum level of SEM chamber via leakage control. Plane view in-situ observation provides better understanding on the overall feature of recrystallization phenomena and cross sectional in-situ observation provides clearer understanding on the recrystallization mechanism.

Key Words: Electron backscatter diffraction, In-situ heating, Surface pinning, Interstitial free steel, Recrystallization

\section{INTRODUCTION}

Interstitial free (IF) steels and bake hardenable (BH) steels are one of most frequently used steel sheets for an automotive exterior. An excellent deep drawability is required for both steels to apply press forming process for automotive body making. It is typical alloy design concept to add strong carbide or nitride formers such as $\mathrm{Ti}$ and $\mathrm{Nb}$, which gather the carbon and nitrogen atoms from solid solution and instead incorporate them into complex precipitates because solute carbon and nitrogen are harmful elements for formability (Takechi, 1994). It is well known that the average crystallographic orientation distribution of materials is an another essential parameter to determine the formability of extra low carbon steels such as IF steels and BH steels (Ray et al., 1994). The excellent deep drawability can be achieved by proper texture control. It is also well known that $\alpha$-fiber $(<110>/ /$ sample rolling direction, $\mathrm{RD})$ and $\gamma$-fiber $(\{111\} / /$ sample normal direction, ND) texture is developed in cold rolled state, while $\alpha$-fiber texture weakens and $\gamma$-fiber texture strengthens after recrystallization (Hutchinson, 1984; Emren et al., 1986; Ray et al., 1994). The development of $\gamma$-fiber texture enhances the formability of extra low carbon steels dramatically and the mechanism of $\{111\} / / \mathrm{ND}$ texture was investigated by previous researchers intensively (Ray et al., 1994; Kim et al., 2002; Choi \& Cho, 2005).

For the past couple of decades, many experimental investigations have been carried out to understand their micro-

(a) This is an open-access article distributed under the terms of the Creative Commons Attribution Non-Commercial License (http://creativecommons.org/licenses/by-nc/3.0) which permits unrestricted noncommercial use, distribution, and reproduction in any medium, provided the original work is properly cited.

Copyrights @ 2013 by Korean Society of Microscopy 
texture development using electron backscatter diffraction (EBSD) (Kim et al., 2002; Quadir \& Duggan, 2006), X-ray diffraction (Samajdar et al., 1998a, 1998b), transmission electron microscopy (TEM) (Thomas et al., 2003) and neutron diffraction technologies (Hansen et al., 1981). In particular, EBSD based on a scanning electron microscopy (SEM) technique has been widely used for the direct and local texture measurement in deformed and annealed samples. This technique is very useful because it can collect the microstructure and grain orientation information at the same time. Many EBSD investigations of IF steel have been carried out (Hashimoto et al., 1998; Barnett \& Kestens, 1999; Kim et al., 2002; Quadir \& Duggan, 2004; Quadir \& Duggan,
2006; Tse \& Duggan, 2006). However, these experiments mostly have been undertaken by post-mortem examination of annealed and quenched samples.

In-situ observations have significant advantages of evaluating sequential microstructural changes through direct observation of the deformed and recrystallized states. Several in-situ SEM studies of recrystallization have been carried out on $\mathrm{Al}$ (Hurley \& Humphreys, 2004) and $\mathrm{Cu}$ (Mirpuri et al., 2006), which have moderate recrystallization temperatures. There have been some observations of the recrystallization process of IF steels through in-situ heating stage combined with EBSD (Seaton \& Prior, 2004; Nakamichi et al., 2007; Nakamichi et al., 2008). It is difficult to carry out in-situ heating experiments in IF steels

A
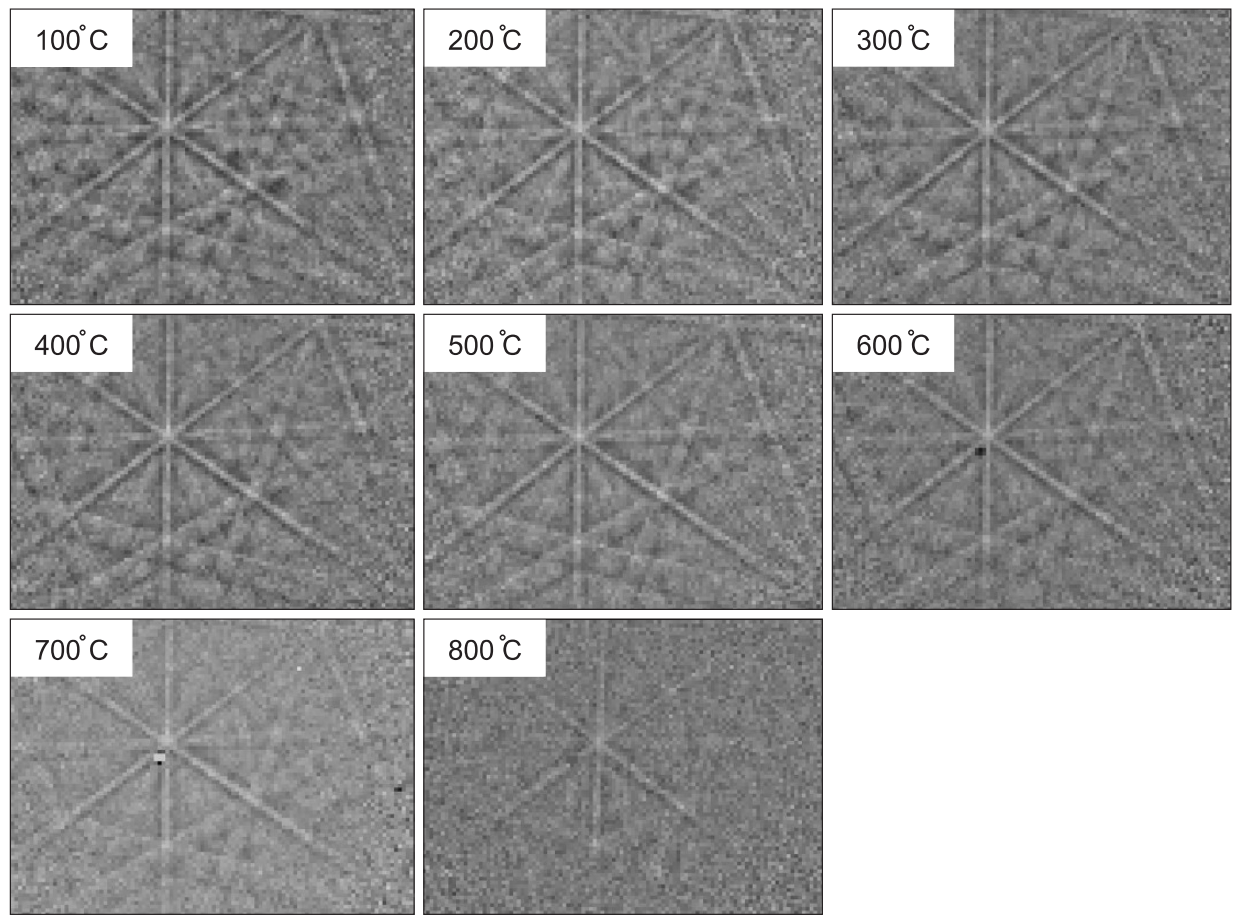

\section{B}

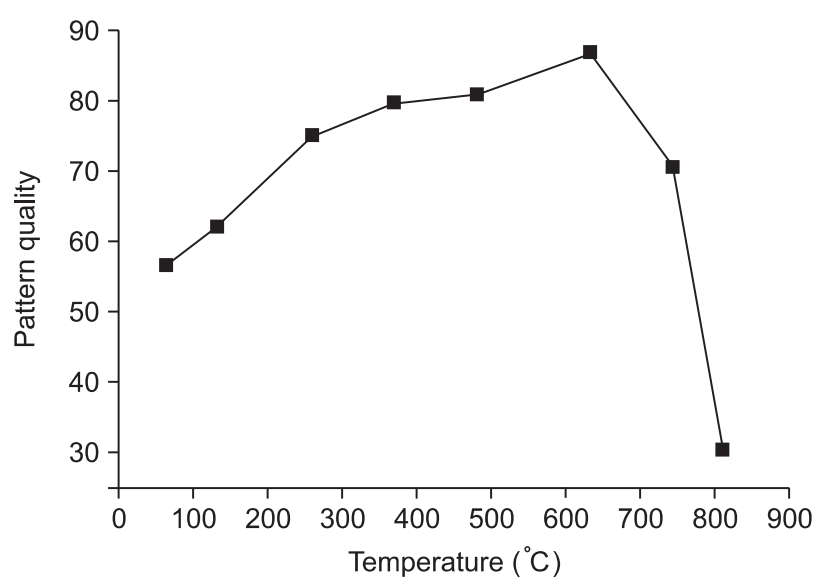

Fig. 1. (A) Electron backscatter diffraction patterns acquired at various specimen temperatures in pure $\mathrm{Cu}$. (B) Average pattern quality value change according to specimen temperature. 
because of their relatively high recrystallization temperatures $\left(>700^{\circ} \mathrm{C}\right)$. Many researchers faced difficulties such as heating stage stability, thermal electron emissions, and incomplete recrystallization during in-situ EBSD experiments (Nakamichi et al., 2007; Nakamichi et al., 2008; Wright \& Nowell, 2009). In the present work, technical investigation to figure out the problems arising during in-situ heating EBSD analysis such as image drift and surface microstructure pinning problems were carried out. Image drift problem was suppressed by introducing constant current supplying mode. A surface pinning problem caused by $\mathrm{TiO}_{2}$ oxide particles was reduced by platinum and carbon dual-layer coating and overcome by improvement of vacuum level of SEM chamber. The recrystallization behaviors of IF steel and $\mathrm{BH}$ steel observed by in-situ heating EBSD experiments were also discussed.

\section{MATERIALS AND METHODS}

Eighty percent of cold rolled $0.06 \mathrm{wt} \% \mathrm{Ti}$ added IF steel and $\mathrm{Cu}$ added $\mathrm{BH}$ steel were used for the in-situ heating EBSD experiments. Both steels are extra low carbon steel grade and the carbon contents of both steels do not exceed $0.002 \mathrm{wt} \%$. IF steel sheet with $0.8 \mathrm{~mm}$ thickness was cut in rectangle coupons of $10 \mathrm{~mm}$ along RD and $7 \mathrm{~mm}$ along transverse direction (TD) for the sheet normal section observation and $\mathrm{BH}$ steel sheet with $0.6 \mathrm{~mm}$ thickness was cut in rectangle pieces of $8 \mathrm{~mm}$ along $\mathrm{RD}$ and $1 \mathrm{~mm}$ along TD for the sheet transverse section observation. All rectangles were grinded by $\mathrm{SiC}$ paper up to 2,000 grit, and then they were electro polished at $-30^{\circ} \mathrm{C}$ under $18 \mathrm{~V}$ for 45 seconds. For the electrolyte, a $10 \%$ perchloric acid and 90\% ethyl alcohol solution was used. Insitu heating experiments were carried out with heating stage (MZ.H8; Kammrath-Weiss, Dortmund, Germany) which can be heated up to $850^{\circ} \mathrm{C}$. EBSD maps were collected using Schottky type field emission gun (FEG) SEM (S-4300SE; Hitachi, Tokyo, Japan) equipped with a high sensitivity type EBSD system (CrystAlign e-FlashHR; Bruker, Berlin, Germany) and a high speed type EBSD system (Channel 5 Norlys F; HKL, Hobro, Denmark). EBSD maps acquired before and after in-situ experiment at room temperature had 0.2 0.25 $\mu \mathrm{m}$ step size and maps acquired during in-situ experiments were taken with increased step size of $0.8 \sim 1.0 \mu \mathrm{m}$ to keep the duration time for each map within 10 minutes. TEM analysis was carried out by FEG type TEM (JEM3000F; JEOL, Tokyo, Japan) equipped with energy dispersive X-ray spectroscopy (EDS; INCA, Oxford, UK). Samples for the TEM analysis were prepared by focused ion beam (FIB) (NOVA 200; FEI, Hillsboro, OR, USA).

\section{RESULTS AND DISCUSSION}

Before the in-situ heating experiment, EBSD pattern quality variations according to the specimen temperatures were confirmed. Fig. 1A shows the EBSD patterns acquired from pure $\mathrm{Cu}(99.99 \mathrm{wt} \%)$ at various temperatures. As shown in Fig. $1 \mathrm{~B}$, average quality of patterns did not degrade up to $700^{\circ} \mathrm{C}$, furthermore it improved. It started to degrade over $750^{\circ} \mathrm{C}$ rapidly and it was hard to index with typical indexing scheme. Fig. 2A shows EBSD patterns acquired from IF steel. A distinct pattern was acquired and there was no degradation even at $817^{\circ} \mathrm{C}$. It is interesting that there was a rapid degradation in $\mathrm{Cu}$ over $750^{\circ} \mathrm{C}$ but not in IF steel. The reason why there was no degradation in steel even at over $800^{\circ} \mathrm{C}$ is related to the thermal vibration of materials. Sharma and Singh reported mean square amplitude of thermal vibration in cubic materials as equation. (1) (Sharma \& Singh, 1969).

$$
\mathrm{x}_{m}=\frac{k T}{M N R^{2}} \sum_{q, p} w_{q, p}^{-2}
$$

Where $\mathrm{M}$ is the ionic mass, $\mathrm{N}$ is the number of ions per unit volume, $\mathrm{k}$ is Boltzmann constant, $\mathrm{T}$ is the absolute temperature and $\mathrm{w}_{\mathrm{q}, \mathrm{p}}$ is the angular frequency of a phonon of wave vector $\mathrm{q}$ and polarization $\mathrm{p}$.

The mean square amplitudes of thermal vibration calculated by equation. (1) from the reported data (Sharma \& Singh,
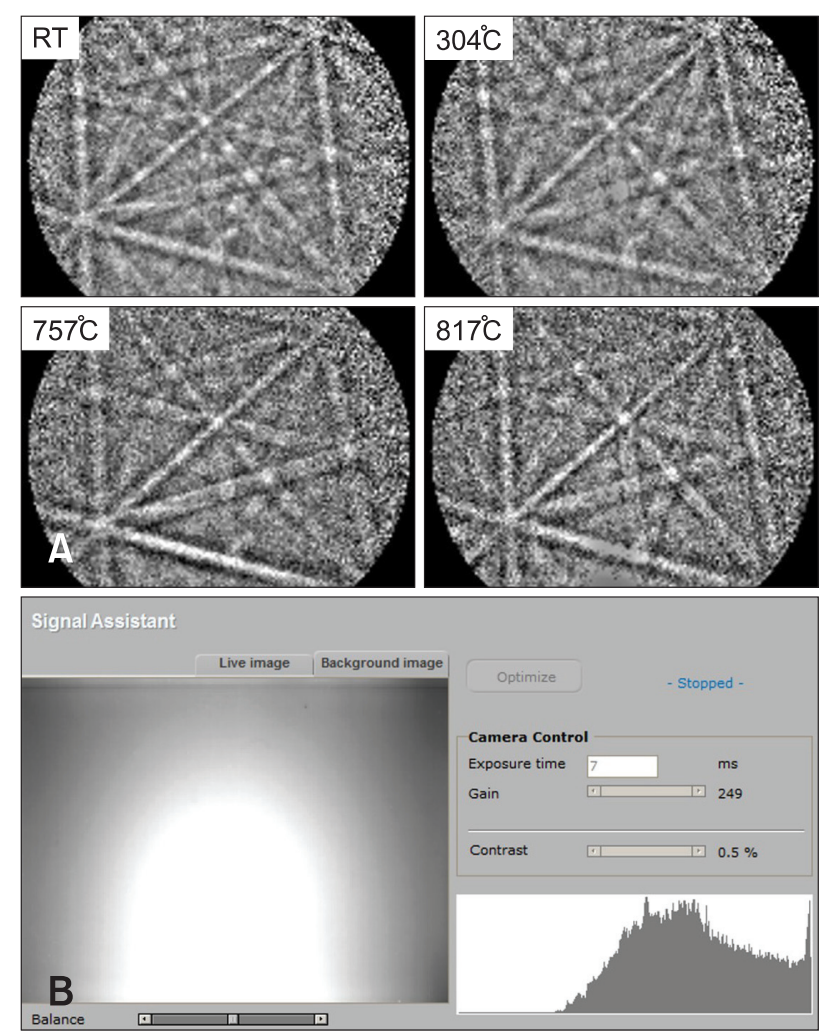

Fig. 2. (A) Electron backscatter diffraction patterns acquired at various specimen temperatures (room temperature [RT], $304^{\circ} \mathrm{C}, 757^{\circ} \mathrm{C}$, and $817^{\circ} \mathrm{C}$ ) in interstitial free steel. (B) A captured image of background collected at $800^{\circ} \mathrm{C}$. 

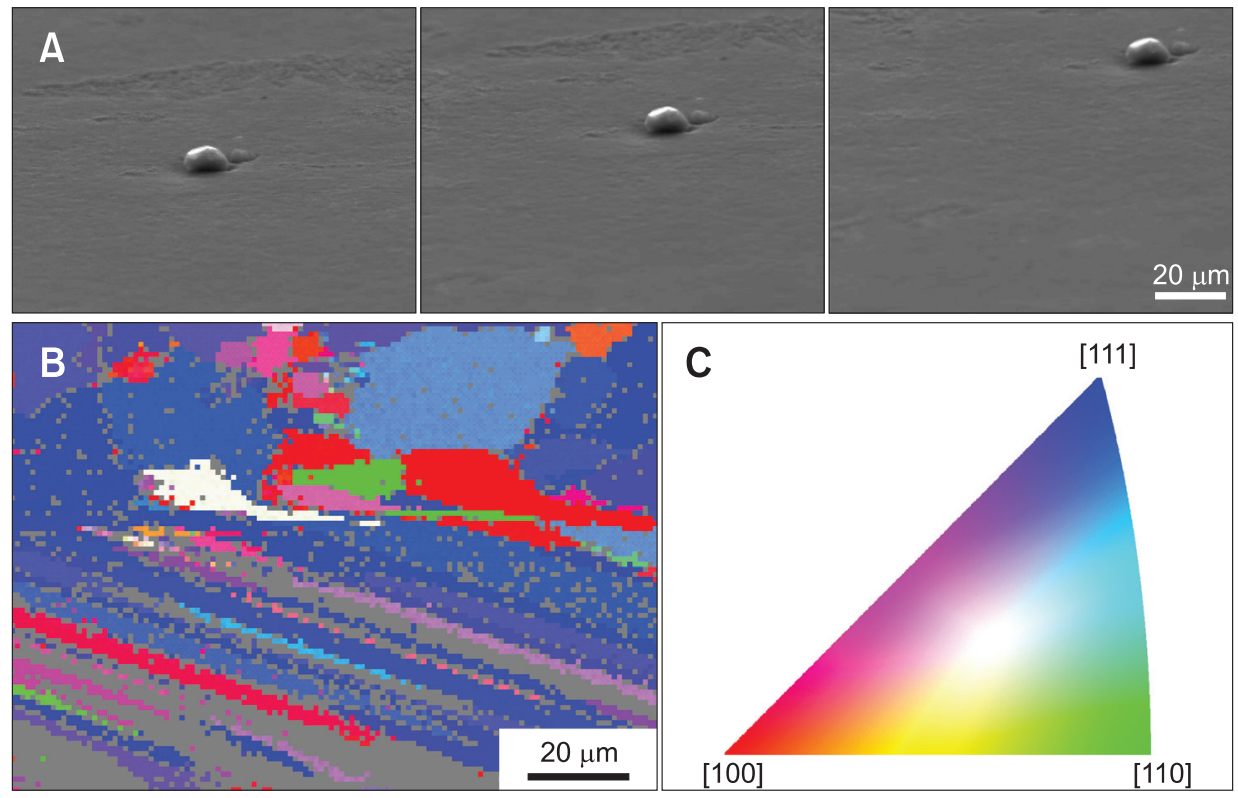

c
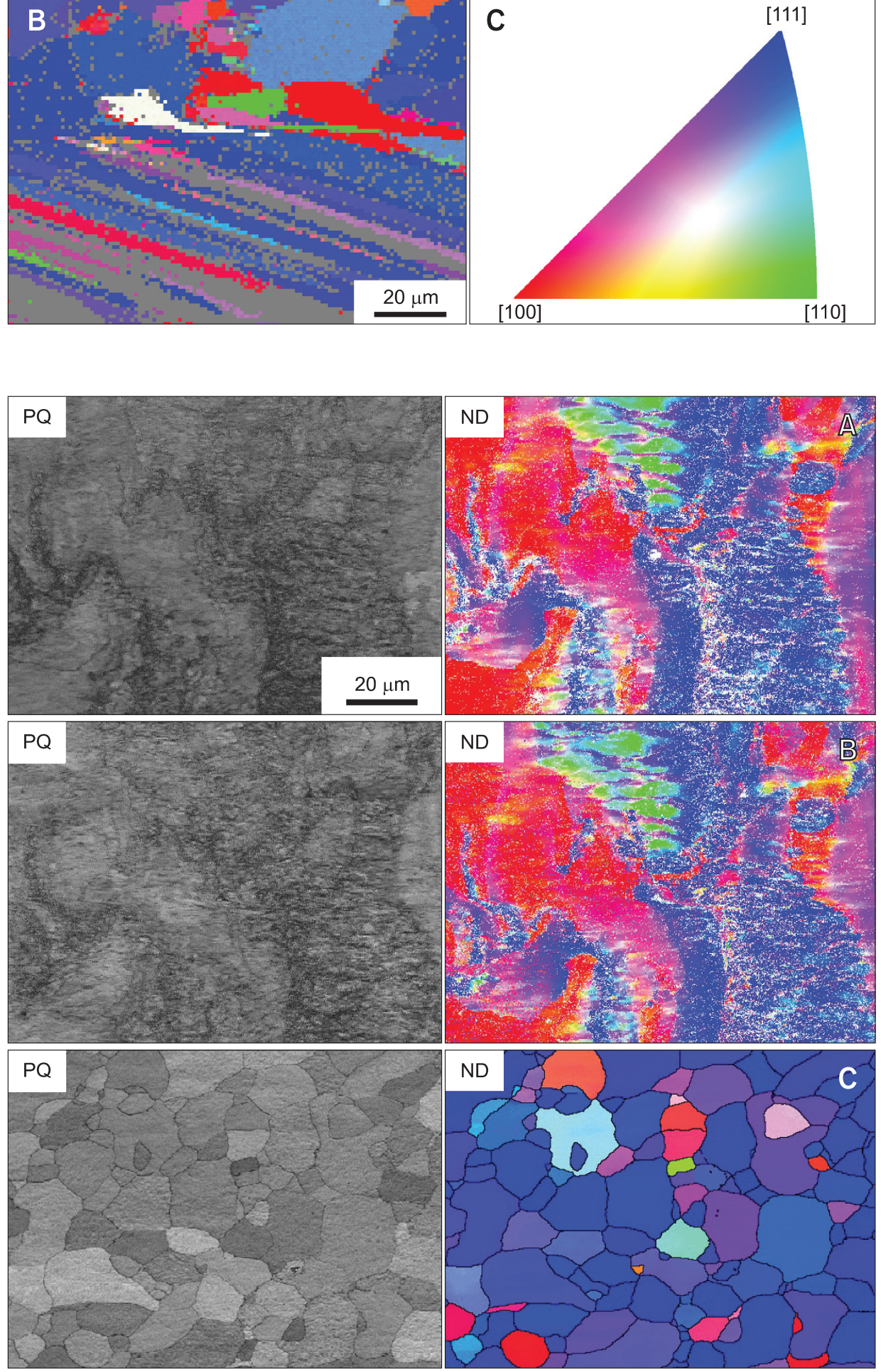

Fig. 3. (A) Sequential pictures captured during in-situ heating. (B) Sample normal direction inverse pole figure map acquired by in-situ electron backscatter diffraction test. (C) Colorkey for inverse pole figure map of cubic material.
Fig. 4. Pattern quality maps and sample normal direction inverse pole figure maps (A) Acquired at room temperature before in-situ electron backscatter diffraction experiment (cold rolled state). (B) Acquired at room temperature after in-situ annealing at $750^{\circ} \mathrm{C}$ for 1 hour and cooling. (C) Acquired after 100 $\mu \mathrm{m}$ grinding with the specimen of (B). $\mathrm{PQ}$, pattern quality; ND, normal direction. 
1969) are 0.00807 for $\mathrm{Fe}$ and 0.0115 for $\mathrm{Cu}$ at $800^{\circ} \mathrm{C}$. The amplitude of vibration in $\mathrm{Cu}$ is around half portion larger than that of Fe. Larger amount of vibration deteriorate the atomic arrangement for the stronger diffraction and increases the noise level of the EBSD pattern as shown in the pattern at $800^{\circ} \mathrm{C}$ in Fig. 1A. It is also noteworthy that the average pattern quality was increasing up to $700^{\circ} \mathrm{C}$. It is because the total amount of backscattered electron increases according to the material temperature increase. It also raises the total number of informative signal and improves the signal to noise ratio, which resulted in better pattern quality value. Fig. $2 \mathrm{~B}$ shows the hot spot formation near pattern center area during static background collection at $800^{\circ} \mathrm{C}$, which means that too many backscattered electrons are emitted at that temperature. We should reduce the exposure time or the camera gain value to get the relevant signal level as room temperature observation. Fig. 3A shows the sequential secondary electron images taken during heating, which indicates an image drift. This image drift problem can occur not only during heating but also during temperature maintaining step as shown in Fig. $3 \mathrm{~B}$ in a target temperature control mode. In the target temperature controlling mode, supplied voltage and current are continuously changed to keep the temperature as a constant value, which may cause a sudden image drift like Fig. 3B. To prevent this problem, a constant current control mode was adapted. In this mode, a saturation temperature was determined according to supplied current. Even though temperature can slightly increase around the saturation temperature, an image drift near saturation temperature is negligible considering typical map acquisition time during insitu EBSD experiment, 5 10 minutes.

As the image drift problem has figured out, several in-situ experiments to understand recrystallization phenomena of IF steels were carried out at $650 \sim 750^{\circ} \mathrm{C}$. According to the previous postmortem study on the same materials by static temperature annealing (Kim et al., 2002), the specimen should be fully recrystallized by an annealing at $650^{\circ} \mathrm{C}$ for 30 minutes. But there was almost no change in the microstructure by insitu heating at $750^{\circ} \mathrm{C}$ for 1 hour as shown in Fig. $4 \mathrm{~A}$ and B. We could not understand this result so we grinded the specimen of Fig. 4B for $100 \mu \mathrm{m}$ and observed almost same area as the site observed in Fig. 4A and B. Surprisingly the specimen
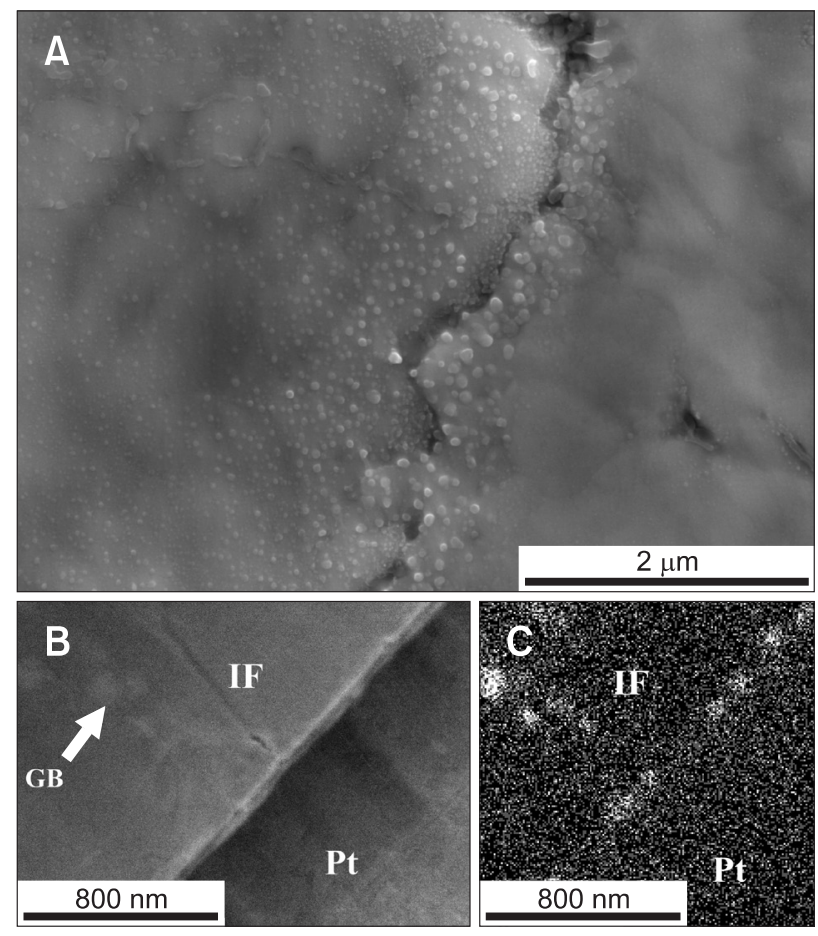

Fig. 5. (A) A secondary electron micrograph acquired by scanning electron microscopy. (B) A high angle annular dark field image acquired by transmission electron microscopy (TEM). (C) Ti elemental map acquired by TEM energy dispersive X-ray spectroscopy. IF, interstitial free; GB, grain boundary; Pt, platinum.
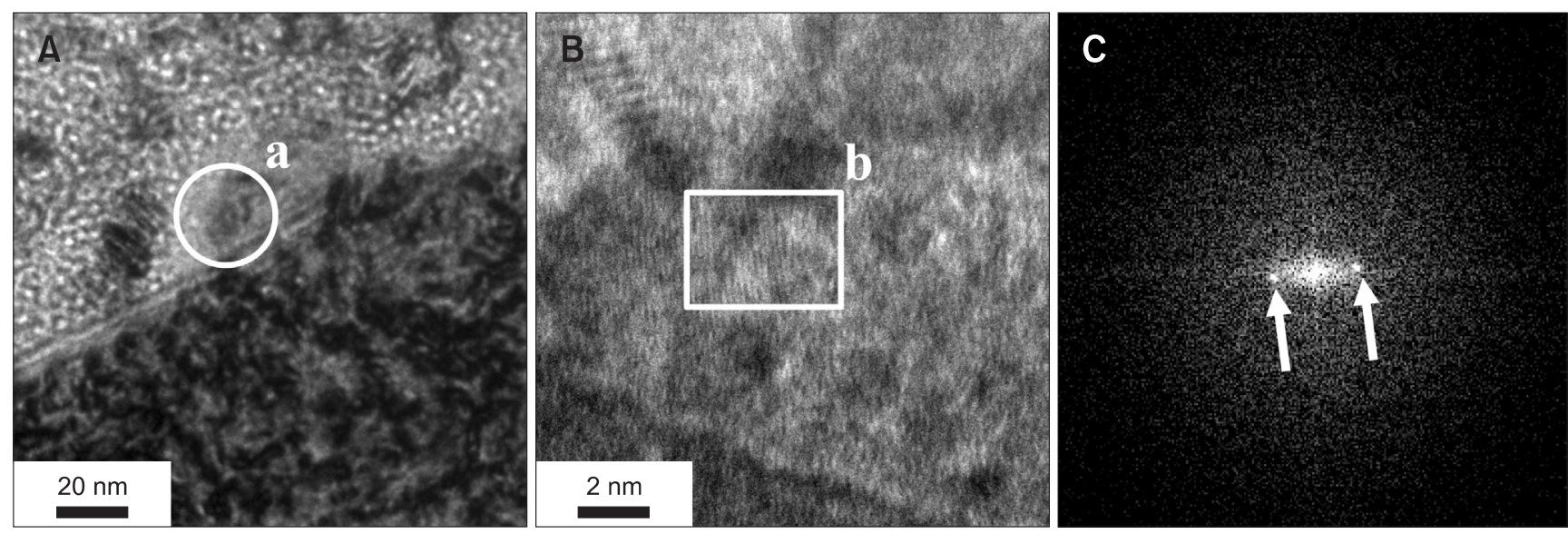

Fig. 6. (A) A bright field image acquired by TEM. (B) A high resolution image acquired from the area of 'site a' in (A). (C) Fast Fourier transformed image (arrows) of 'site b' in (B). 
was already fully recrystallized as shown in Fig. 4C. We tried to find the reason by microstructural analysis on the surface of the specimen after same heat treatment as Fig. 4B case in SEM chamber. With the careful observation with FEG SEM, we found many 10 to $100 \mathrm{~nm}$ sized sphere type particles were generated especially at the grain boundary area of elongated deformed grains as shown in Fig. 5A. A TEM specimen was prepared with FIB from the grain boundary area of elongated deformed grain. Fig. 5B shows a high angle annular diffraction image acquired by TEM. From this image we could find some particles with brighter contrast than matrix which had higher atomic mass was observed not only on the surface but also along grain boundary. Fig. 5C shows a Ti element distribution map acquired by TEM EDS. From this image we could figure out those brighter particles observed in Fig. 5B were Ti containing particles. We also observed the Ti containing particles with high resolution image mode as shown in Figs. $6 \mathrm{~A}$ and $6 \mathrm{~B}$. According to the Fig. $6 \mathrm{C}$ which is the fast Fourier transformed image of site $\mathrm{b}$ in Fig. 6B, the d-spacing of observed plane is $2.141 \AA$. This value is well matched with the d-spacing of $\mathrm{TiO}_{2}$ (111) plane which is $2.163 \AA$ (JCPDS PDF \# 881175). From these evidences we reach a conclusion that in spite of the low oxygen partial pressure inside SEM chamber, Ti can compose $\mathrm{TiO}_{2}$ sphere type particles on the surface and at the grain boundaries of the deformed grains, which cause surface microstructure pinning during in-situ heating experiments. To confirm whether the $\mathrm{TiO}_{2}$ particles caused the surface microstructure pinning, several in-situ heating
EBSD experiments with pure $\mathrm{Cu}$, pure $\mathrm{Fe}$, and $\mathrm{Nb}$ added IF steel were carried out. All of these samples were perfectly analyzed by in-situ heating EBSD experiments without surface microstructure pinning problem.

To prevent this surface microstructure pinning in Ti added IF steel, protective coating on the sample surface was considered. As shown in Fig. 7A, carbon coated on the sample was burned out at around $550^{\circ} \mathrm{C}$. During this burning process, it was expected that the oxygen level inside SEM chamber was slightly reduced. But the carbon coating was not sufficient to prevent oxidation during in-situ heating experiment, a dual layer coating, a thin platinum coating followed by a carbon coating was introduced. It is well known that the maximum depth of EBSD pattern formation is limited to the $50 \mathrm{~nm}$ from the sample surface (Randle \& Engler, 2000). So it is recommended that the total thickness of coating layer is limited to the $10 \mathrm{~nm}$ to keep the EBSD patterns from degrading. Fig. 7B shows sample ND inverse pole figure maps acquired from cold rolled, 30 minutes annealed at $700^{\circ} \mathrm{C}$, and 60 minutes annealed at $700^{\circ} \mathrm{C}$ samples after dual layer coating. There was no specific degradation of mapping quality by dual layer coating and the surface microstructure pinning problem was fairly suppressed by dual layer coating. But there still remained unrecrystallized regions in some grains.

To accomplish the perfect prevention of surface microstructure pinning during in-situ EBSD experiments, a vacuum leakage check with $\mathrm{He}$ gas was carried out. We could find a slight leakage from the in house made SEM attachment and repaired
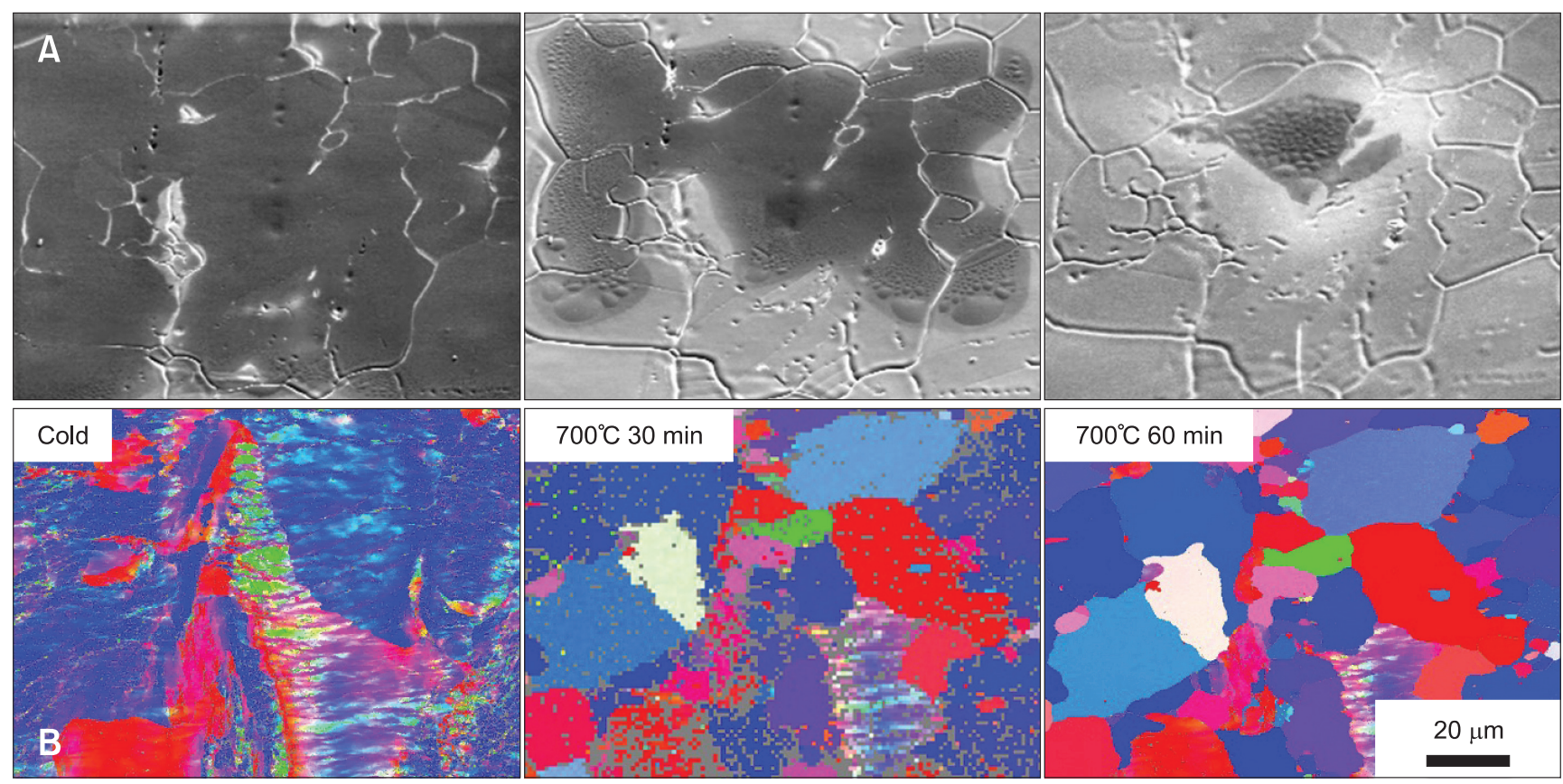

Fig. 7. (A) Sequential pictures captured during in-situ heating during $550^{\circ} \mathrm{C}$ annealing after carbon coating. (B) sample normal direction inverse pole figure maps after platinum-carbon multi-layer coating in cold rolled, $700^{\circ} \mathrm{C} 30$ minutes annealed, and $700^{\circ} \mathrm{C} 60$ minutes annealed state. 
it. With this treatment, the vacuum level of SEM chamber was enhanced from $5 \times 10^{-5}$ Torr to $7.5 \times 10^{-6}$ Torr. As shown in Fig. 8 , the surface microstructure pinning problem was perfectly prevented by combination of vacuum level improvement and dual layer coating.

Fig. 8 shows in-situ heating EBSD experiment results of
Ti added IF steel in plane view condition. With plane view observation, it is easier to understand overall recrystallization behaviors of materials. For the Ti added IF steel, we can notice that the recrystallized grains with $\{111\} / / \mathrm{ND}$ orientation generated from $\{111\} / / N D$ deformed grains were main sources to determine final orientation of fully recrystallized
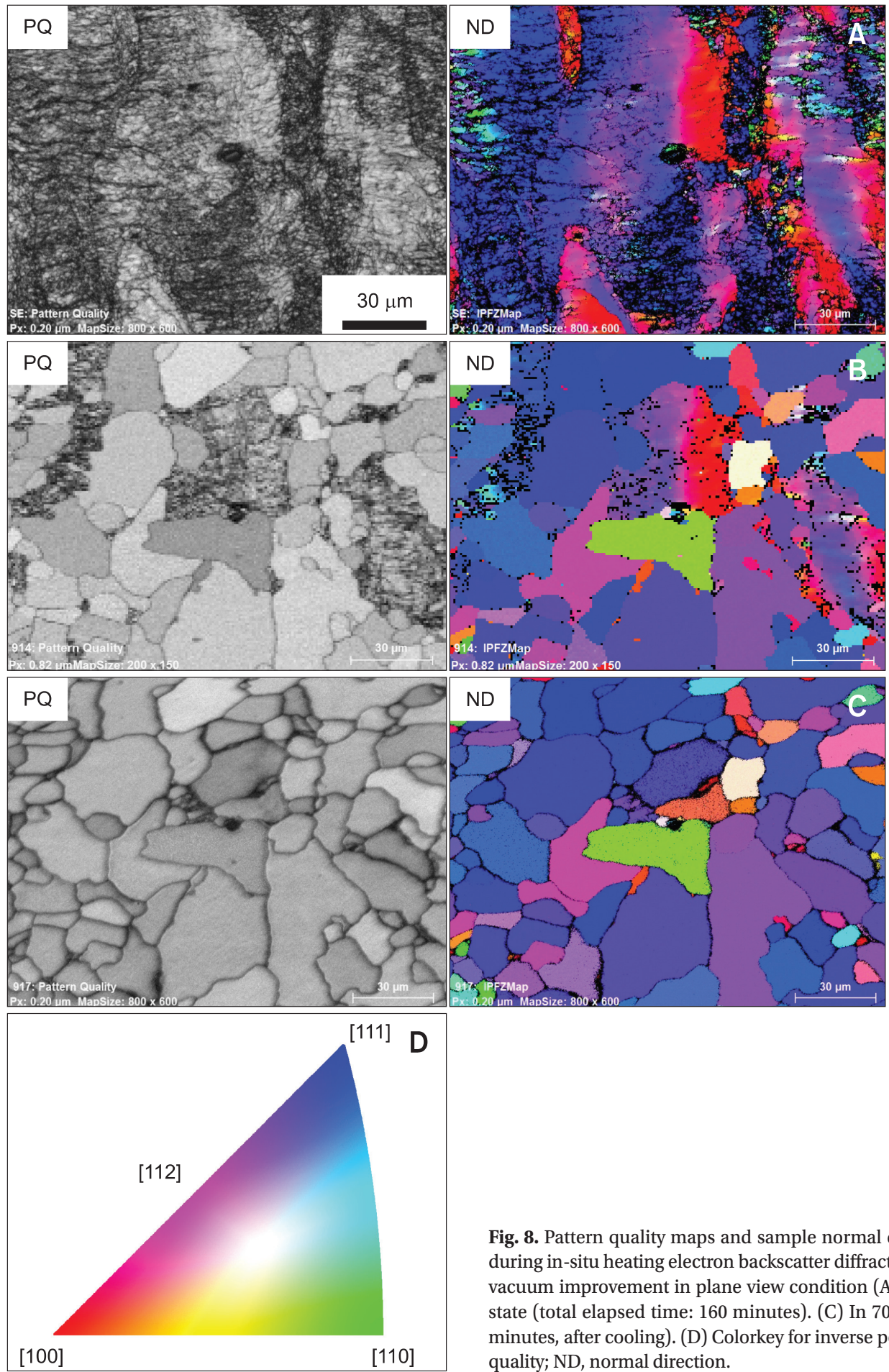

Fig. 8. Pattern quality maps and sample normal direction inverse pole figure maps acquired during in-situ heating electron backscatter diffraction experiments of interstitial free steel after vacuum improvement in plane view condition (A) In cold rolled state. (B) In $700^{\circ} \mathrm{C}$ annealed state (total elapsed time: 160 minutes). (C) In $700^{\circ} \mathrm{C}$ annealed state (total elapsed time: 300 minutes, after cooling). (D) Colorkey for inverse pole figure map of cubic material. PQ, pattern quality; ND, normal direction. 
specimen. It is also observed that several recrystallized grains with various orientations were generated at the grain boundaries of elongated deformed grains or orientation transition region inside deformed grains. But those grains did not grow effectively to affect the final orientation of fully recrystallized sample.

Fig. 9 shows in-situ heating EBSD experiment results of
$\mathrm{Cu}$ added $\mathrm{BH}$ steel in cross-section view condition. With cross-section view observation, more information for the recrystallization mechanism can be acquired. It is same as the IF steel case that the recrystallization started from the deformed grains with $\{111\} / / N D$ orientation. Furthermore it is clear that the recrystallized grains generated from the deformation bands which were $45^{\circ}$ tilted from the
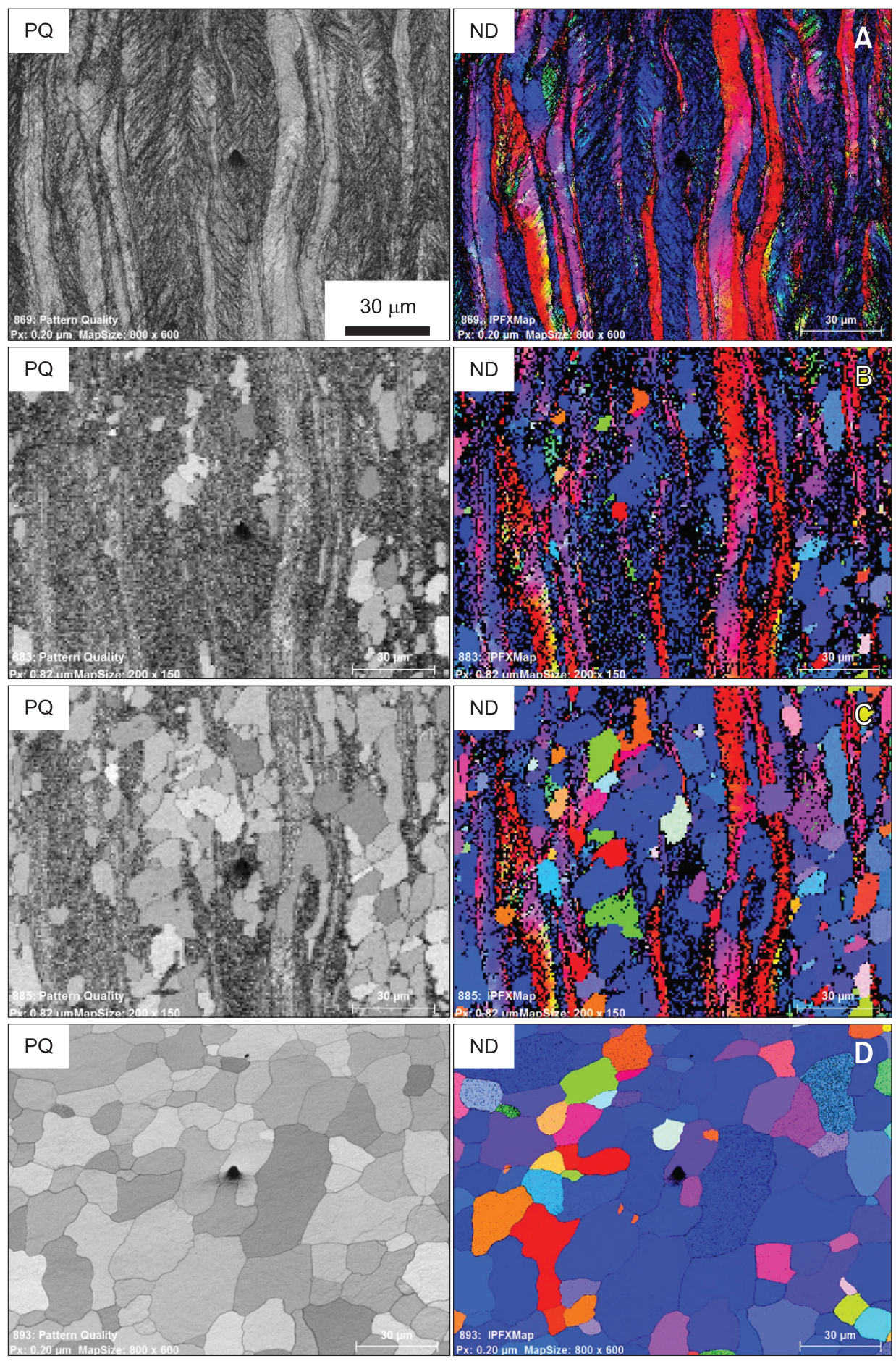

Fig. 9. Pattern quality maps and sample normal direction inverse pole figure maps acquired during in-situ heating electron backscatter diffraction experiments of bake hardenable steel in cross-section view condition (A) In cold rolled state. (B) In $600^{\circ} \mathrm{C}$ annealed state (total elapsed time: 140 minutes). (C) In $610^{\circ} \mathrm{C}$ annealed state (total elapsed time: 160 minutes). (D) In $820^{\circ} \mathrm{C}$ annealed state (total elapsed time: 270 minutes, after cooling). 
$\mathrm{RD}$ (elongated direction in pattern quality map). But the generation and growth kinetics of recrystallized grains strongly depends on the orientation consistency inside deformed grains. In case that the deformed $\{111\}$ grains have orientation deviation inside grain, the generation of recrystallized grains started from the early stage of recrystallization. In case that the deformed $\{111\}$ grains have unique orientation inside grain like bottom middle $\{111\}$ grain in Fig. 9A, the recrystallization is delayed until the later stage of recrystallization as shown in Fig. 9C. But the growth kinetics of recrystallized grains from this type grains is fast enough to compensate the delayed generation as shown in Fig. 9D. Both high frequency of recrystallized grain generation in orientation deviated $\{111\}$ grains and fast grain growth kinetics of recrystallized grain in $\{111\}$ grains with unique orientation explain why the recrystallization from $\{111\}$ deformed grains determine the final texture of fully recrystallized specimens.

\section{CONCLUSIONS}

Various technical approaches to solve the problems during insitu heating EBSD experiments was carried out and following conclusions were drawn.

1. EBSD patterns are successfully acquired up to $830^{\circ} \mathrm{C}$ in steels.
2. Image drift problem during in-situ EBSD experiments can be suppressed by the constant current supply during heating.

3. Surface microstructure pinning was observed in Ti added steels due to $\mathrm{TiO}_{2}$ sphere type particles formation on the sample surface and at the grain boundaries of elongated deformed grains. This problem can be reduced by platinum and carbon dual layer coating and perfectly prevented by improving the vacuum level inside SEM chamber.

4. For the recrystallization of IF steel, the recrystallized grains with $\{111\} / / N D$ orientation generated from $\{111\} / / N D$ deformed grains determined the final texture of fully recrystallized samples.

5. For $\mathrm{Cu}$ added $\mathrm{BH}$ steel, recrystallization started from the deformation band with $\{111\} / / N D$ orientation. In case that there was no orientation deviation within deformed grain, the generations of recrystallized grains were delayed but the fast growth rate of those recrystallized grains compensated the delayed generation during the later stage of recrystallization.

\section{ACKNOWLEDGMENTS}

The authors gratefully acknowledge the support provided by KIST (Grant Numbers 2E24022 and 2E24043).

\section{REFERENCES}

Barnett M R and Kestens L (1999) Formation of $\{111\}<110>$ and $\{111]<112>$ textures in cold rolled and annealed IF sheet steel. ISIJ Int. 39, 923-929.

Choi S H and Cho J H (2005) Primary recrystallization modelling for interstitial free steels. Mater. Sci. Eng. A, 405, 86-101.

Emren F, von Schlippenbach U, and Lücke K (1986) Investigation of the development of the recrystallization textures in deep drawing steels by ODF analysis. Acta Metall. 34, 2105-2117.

Hansen N, Leffers T, and Kjems J K (1981) Recrystallization kinetics in copper investigated by in situ texture measurements by neutron diffraction. Acta Metall. 29, 1523-1533.

Hashimoto N, Yoshinaga N, and Senuma T (1998) Texture evolution of IF steel due to recrystallization. ISIJ Int. 38, 617-624.

Hurley P J and Humphreys F J (2004) A study of recrystallization in singlephase aluminium using in-situ annealing in the scanning electron microscope. J. Microsc. 213, 225-234.

Hutchinson W B (1984) Development and control of annealing textures in low-carbon steels. Int. Mater. Rev. 29, 25-42.

Kim D I, Oh K H, Lee H C, and Lee D N (2002) Statistical analysis of the development of recrystallization texture in IF steel. Mater. Sci. Forum 408-412, 839-844.

Mirpuri K, Wendrock H, Menzel S, Wetzig K, and Szpunar J (2006) Texture evolution in Copper film at high temperature studied in situ by electron back-scatter diffraction. Thin Solid Films 496, 703-717.

Nakamichi H, Humphreys F J, Bate P S, and Brough I (2007) In-Situ EBSD Observation of the Recrystallization of an IF Steel at High Temperature. Mater. Sci. Forum 550, 441-446.

Nakamichi H, Humphreys F J, and Brough I (2008) Recrystallization phenomena in an IF steel observed by in situ EBSD experiments. J. Microsc. 230, 464-471.

Quadir M Z and Duggan B J (2004) Deformation banding and recrystallization of $\alpha$ fibre components in heavily rolled IF steel. Acta Mater. 52, 4011-4021.

Quadir M Z and Duggan B J (2006) A microstructural study of the origins of y recrystallization textures in $75 \%$ warm rolled IF steel. Acta Mater. 54, 4337-4350.

Randle V and Engler O (2000) Introduction to Texture Analysis: Macrotexture, Microtexture and Orientation Mapping (Gordon and Breach Science Publishers, Singapore).

Ray R K, Jonas J J, and Hook R E (1994) Cold rolling and annealing textures in low carbon and extra low carbon steels. Int. Mater. Rev. 39, 129-172.

Samajdar I, Verlinden B, Kestens L, and Van Houtte P (1998a) Physical parameters related to the developments of recrystallization textures in an ultra low carbon steel. Acta Mater. 47, 55-65.

Samajdar I, Verlinden B, and Van Houtte P (1998b) Development of 
recrystallization texture in IF-steel: an effort to explain developments in global texture from microtextural studies. Acta Mater. 46, 2751 2763.

Seaton N C A and Prior D J (2004) Nucleation during recrystallisation in Ti-SULC steel. Mater. Sci. Forum 467-470, 93-98.

Sharma P K and Singh N (1969) Mean square amplitude of thermal vibrations in cubic metals at melting point. Chem. Phys. Lett. 4, 1-2.

Takechi H (1994) Metallurgical aspects on interstitial free sheet steel from industrial viewpoints. ISIJ Int. 34, 1-8.
Thomas I, Zaefferer S, Friedel F, and Raabe D (2003) High-resolution EBSD investigation of deformed and partially recrystallized IF steel. Adv. Eng. Mater. 5, 566-570.

Tse Y Y and Duggan B J (2006) Orientation imaging microscopy studies of recrystallization in interstitial-free steel. Metall. Mater. Trans. A 37, 1055-1064.

Wright S I and Nowell M M (2009) Electron Backscatter Diffraction in Materials Science, pp. 329-344, (Springer, New York). 